\title{
As práticas de responsabilidade social de empresas modelo em sustentabilidade
}

\author{
Practices of corporate social responsibility in \\ sustainability model
}

\author{
Franciéle Fanaia de Oliveira ${ }^{1}$ \\ Rosamaria Cox Moura-Leite ${ }^{2}$
}

\section{Resumo}

As ações de responsabilidade social desenvolvidas pelas organizações não devem ser realizadas de forma abstrata, mas atreladas ao negócio em que atuam e em benefício da comunidade do entorno do local em que estão instaladas. A utilização dessas práticas caracteriza o uso da responsabilidade social empresarial estratégica, já que proporciona benefício mútuo para as partes envolvidas. Do mesmo modo, as ações também podem apresentar práticas de natureza responsiva que ocorrem quando as empresas desenvolvem ações com o intuito de reduzir os danos da cadeia de valor e ser uma boa cidadã (PORTER; KRAMER, 2006). Desse modo, o presente trabalho tem como objetivo descrever as ações de responsabilidade social das empresas referências nessa área, nos seus respectivos setores, e identificar se as ações realizadas por elas podem ser classificadas como estratégicas ou responsivas. A metodologia da pesquisa seguiu o modelo indutivo, descritivo-analítico, qualitativo, e adotou o método da análise de conteúdo para coletar as informações divulgadas sobre responsabilidade social na internet. Foram analisadas duas empresas de dois setores conhecidos pela propensão à adoção de práticas de responsabilidade social: o setor de cosméticos e o setor de energia. Nesse sentido, o estudo da temática torna-se relevante tanto para a academia quanto para a sociedade em geral, pois as ações estratégicas contribuem para que as organizações se diferenciem em um mercado altamente competitivo e otimizem a utilização dos recursos em benefício da própria empresa e dos grupos de interesses. Por fim, averiguou-se que a maioria das

\footnotetext{
Graduanda em Administração pela Universidade Federal de Mato Grosso do Sul - UFMS; Endereço: Rua Treze de Maio, 1420, Vila Glória, Residencial Tripoli, Bloco B, Apto. 26. Cep:79.004-420 - Campo Grande-MS. E-mail: franciele123@hotmail.com. Cel. (67) 9103-4704

2 Professora Doutora Adjunta do Centro de Ciências Humanas e Sociais da Universidade Federal de Mato Grosso do Sul - UFMS. Caixa Postal 649 - Cidade Universitária 79070-900 Campo Grande-MS. E-mail: rosamariamouraleite@gmail.com Tel.: (67) 3345-3712
} 
ações praticadas pelas empresas estudadas possui um caráter estratégico.

Palavras-chave: Ações. Responsabilidade Social Estratégica. Responsabilidade Social Responsiva.

\section{Abstract}

Social responsibility (SR) developed by organizations should not be made in an abstract manner. Social responsibility activities need to be linked to the business and should benefit the local community. The use of such practices characterizes the use of strategic SR, because it benefits all of the parties involved. Similarly, actions can also present practices with a responsive nature that occur when companies develop actions in order to reduce the damage of the value chain and be a good citizen (PORTER; KRAMER, 2006). Thus, this paper aims to describe the actions of corporate social responsibility developed by strong SR companies in their respective sectors and identify whether the actions taken by them can be classified as strategic or responsive. The methodology used in this research followed an inductive qualitative model and adopted the content analysis method to collect information disclosed on the Internet about SR. We analyzed two companies in two sectors that are known by the propensity to adopt socially responsible practices, these are: the cosmetics industry and the energy sector. In this sense, the study becomes relevant for both academic environment and society in general, because the strategic actions performed by organizations allows them to differentiate themselves in a highly competitive market and optimize the efficient use of resources. Thus, confirming that the majority of actions undertaken by the companies included in this research have a strategic character.

Keywords: Actions. Social Responsibility Strategy. Responsive Social Responsibility.

\section{Introdução}

A responsabilidade social está cada vez mais presente na gestão das organizações, pois se observa a pressão das partes interessadas para que as empresas assumam e diminuam os impactos gerados pelas suas operações. Gerir de forma responsável o negócio, segundo Savitz e Weber (2007), auxilia na proteção da organização por meio da identificação de falhas gerenciais, na redução dos riscos de prejudicar os clientes, proporciona a redução de custos, melhora a produtividade, elimina desperdícios e, por fim, promove o crescimento da empresa 
através da conquista de novos mercados e lançamento de novos produtos.

Sob esse enfoque, Savitz e Weber (2007) asseguram que a empresa sustentável gerencia o negócio com o intuito de gerar benefícios para todas as partes envolvidas com a organização. Diante disso, inferese que estas não realizam ações de responsabilidade social de maneira abstrata. Ao contrário, os projetos e programas implantados buscam sempre atender de forma simultânea os interesses da organização e os da comunidade em que atuam, ou seja, ter uma natureza estratégica. Nas empresas, contudo, existem ações de natureza responsiva. Esta, diferentemente da primeira, procura realizar boas práticas cidadãs e mitigar os impactos da cadeia de valor, mas não geram o benefício mútuo como a ação de responsabilidade social estratégica.

Conforme Porter e Kramer (2006), as corporações devem tomar providências no debate da responsabilidade social, desde que estas estejam atreladas ao ramo de atuação e os benefícios gerados sejam para comunidades no entorno das organizações, pois quando isso ocorre, tanto a empresa quanto todos os envolvidos no processo estabelecem uma relação de "ganho-ganha".

Dessa forma, o presente trabalho tem por objetivo descrever as ações de responsabilidade social de algumas empresas reconhecidas como referências nessa área em seus respectivos setores e identificar se as ações realizadas por elas podem ser classificadas como estratégica ou responsiva. A fim de alcançar a meta proposta, desenvolveu-se uma lista de variáveis baseadas principalmente nos estudos realizados por Calixto (2011) e Ferraz e Rafael (2012). As ações foram agrupadas em: ações no âmbito social e ações no âmbito ambiental. Foram coletados os dados nas páginas web das empresas e identificava-se se o item em análise (se foi uma ação responsiva ou uma ação estratégica para a organização), considerando as características próprias do negócio da empresa e do setor.

O estudo dessa temática torna-se relevante tanto para a academia quanto para a sociedade em geral, pois as ações estratégicas contribuem 
para que as organizações se diferenciem em um mercado altamente competitivo e aperfeiçoe a utilização eficiente dos recursos em benefício da própria empresa e dos grupos de interesses, o que possibilita resultados positivos para todos os envolvidos.

Assim, o trabalho é composto de um referencial teórico sobre a temática: da exposição da metodologia de pesquisa utilizada; da apresentação dos resultados divididos nos respectivos setores que compõem a amostra escolhida; da discussão dos dados obtidos, demonstrando as diferenças e semelhanças encontradas entre os setores e as empresas analisadas, e os motivos que ensejam na classificação de uma prática de responsabilidade social em estratégica ou responsiva; e, por fim, a conclusão da pesquisa.

\section{Responsabilidade social: o compromisso das organizações}

A postura das corporações perante o meio em que está inserida sofreu grandes transformações durante o período de 1980 a 1990, dentre as quais a adoção do ponto de vista contemporâneo, segundo o qual as organizações não possuem obrigações apenas no aspecto econômico, mas também na comunidade em que exercem suas atividades (CERTO et al., 2010).

A alteração na postura das corporações é atribuída a diversos fatores, como o processo de globalização, o poder crescente das organizações de grande porte, a preocupação com problemas ambientais, além da concorrência imposta pelo mercado (CARROLL; SHABANA, 2010; FARIA; SAUERBRONN, 2008; LEE, 2008). A Responsabilidade Social Empresarial (RSE) pode ser descrita como a reação das organizações perante as novas exigências da sociedade e do mercado, em que a geração de valor delas se reflita para todos os stakeholders, priorizando a conduta ética e transparente (KARKOTLI et al., 2006; MCWILLIAMS; SIEGEL, 2006).

O conceito de triple bottom line ( $\mathrm{TBL}$ ), também conhecido por 3P (people, planet e profit) - em português, PPL (pessoas, planeta e 
lucro) -, é adotado por muitas organizações para desenvolver sua responsabilidade social. Ele reflete um conjunto de valores, objetivos e processos que uma organização deve focar para criar valor em três áreas: econômica, social e ambiental (GUARNIER, 2011). O âmbito econômico é responsável pelo fornecimento de produtos, prestação de serviços e maximização dos lucros. Já o aspecto ambiental referese ao bom aproveitamento e à preservação dos recursos naturais, apoiando-se no tripé social, que se relaciona com a partilha de direitos e responsabilidades dos grupos de interesses (LORENZETTI et al., 2008).

Alguns argumentos que justificariam a adoção da responsabilidade social nas organizações seria a realização do papel social, segundo o qual as empresas não visam apenas a rentabilidade econômico-financeira, mas promovem a inclusão social e a mitigação dos impactos ambientais e melhoram a imagem perante os consumidores. Em um mercado competitivo, em que se diferenciar é uma vantagem para as organizações, a utilização dessa nova forma de agir agrega valor à organização, contribui para sua longevidade e proporciona benefícios tanto para os acionistas quanto para a sociedade (GODÓI-DE-SOUSA et al., 2013).

No início do desenvolvimento da SER, pode-se dizer que as ações voltavam-se para a filantropia e AS práticas individuais. Contudo, a necessidade de aplicar eficientemente os recursos, a fim de obter melhores resultados, fez com que as empresas estruturassem as ações de maneira a obter vantagem competitiva (GODÓl-DE-SOUSA et al., 2013; LEE, 2008; MOURA-LEITE; PADGETT, 2012).

\section{A responsabilidade social sob a ótica de Porter e Kramer (2006)}

A RSE tem sido tratada com relativa importância pelos gestores das corporações, visto que a sociedade cada vez mais exige a adoção de uma postura responsável das organizações. No entanto, apenas investir em ações sociais sem que estejam atreladas à estratégia de negócio da empresa não é vantajoso. Assim, a adoção de práticas socialmente 
responsáveis não deve ser genérica ou uma ação filantrópica, mas precisa ser fonte de inovação, oportunidade e vantagem competitiva (PORTER; KRAMER, 2006).

Dessa forma, pode-se dizer que quando a organização visa manter uma relação ampla, ética e transparente com todas as partes interessadas e envolvidas no ambiente de negócio, ela conseguirá agregar valor a partir do momento em que a integração dos stakeholders alinhar-se com a estratégia empresarial, o que inclui as diretrizes organizacionais e a tomada de decisão. A ocorrência disso poderá proporcionar uma vantagem competitiva que pode ser entendida como um benefício estratégico significativo que oferece à organização uma primazia em relação à concorrência e influência na longevidade (FEDATO, 2005).

De acordo com Porter e Kramer (2006), o alcance da vantagem competitiva dar-se-á com a utilização de atividades específicas de RSE pelas empresas. Logo, a fim de atingir benefícios para os negócios, Porter propõe duas ferramentas de análise: a cadeia de valor e o contexto competitivo. A primeira é utilizada para elencar os impactos sociais positivos ou negativos decorrentes das atividades das organizações e, assim, identificar os fatos para serem solucionados e as novas oportunidades de atuação. O segundo consiste em verificar áreas do contexto social que sejam estratégicas, com o intuito de tomar providências quanto às questões sociais que atingem o ambiente em que estão inseridas. Porém, para conhecer e tomar a decisão da área social mais conveniente e benéfica, os autores definem três categorias para as questões sociais: questões sociais genéricas, impactos sociais na cadeia de valor e dimensão social do contexto competitivo (PORTER; KRAMER, 2006). Gonzaga e Kirschner (2010) ressaltam que a classificação da categoria de questão social depende das características da unidade de negócio, da sua localidade e do posicionamento competitivo da empresa.

A primeira categoria não interfere nas operações da empresa nem provoca impacto na competitividade. A segunda atinge diretamente as atividades da organização na realização do negócio. A terceira relacionase com as questões do ambiente externo que impactam na direção e 
exercem influência na concorrência (PORTER; KRAMER, 2006 apud PEREIRA; SOUSA FILHO, 2011).

As questões sociais identificadas como genéricas não estão ligadas à estratégia da organização, não estão elencadas como estritamente relacionadas com as atividades da empresa nem exercem influência no contexto competitivo. Dessa forma, os investimentos realizados não trazem os benefícios esperados pela organização e pelo ambiente externo. Os impactos na sociedade ocasionados pela cadeia de valor descrita (dentro para fora), pelo contrário, visam pesquisar e elencar todas as consequências sociais decorrente das atividades da corporação, positivas ou negativas, a fim de identificarem áreas ou questões prioritárias. Quando se trata de abordar o contexto competitivo, a escolha da área de maior valor estratégico é importante, pois se obterão medidas sociais benéficas tanto para a sociedade quanto para a empresa no que diz respeito ao negócio em que atua (PORTER; KRAMER, 2006).

De acordo com Porter e Kramer (2006), reunir os problemas sociais ocasionados pela atuação operacional das empresas nos seus respectivos grupos é importante para a criação de uma agenda social corporativa. Essa é uma maneira de reduzir os impactos causados e contribuir com a estratégia de negócio por meio da evolução na área social.

Desse modo, classificam a RSE em responsiva e estratégica. A primeira pode ser entendida como a utilização de boas práticas cidadãs e a busca pela redução dos danos inerentes às atividades da cadeia de valor das organizações. Almeja-se, por meio dela, melhorar as relações com os grupos de interesses e contribuir com programas e projetos que estabeleçam metas claras e mensuráveis. Além disso, procura-se estabelecer a melhor forma de gestão para solucionar os impactos da cadeia de valor do negócio (PORTER; KRAMER, 2006).

A RSE estratégica procura avançar em relação aos aspectos abrangidos pela responsiva. Ela investe em fatores do contexto no qual a organização está inserida que reforcem a competitividade. Para Porter e Kramer (2006), quanto mais ligada ao negócio da empresa for uma 
questão social, melhor será o crescimento da capacidade e dos recursos da organização, além de trazer benefícios efetivos para a sociedade.

A utilização da responsabilidade social estratégica ou responsiva pelas organizações direciona os investimentos para questões sociais que afetam o ambiente em que estão inseridas. Conforme o problema social abordado, pode-se caracterizar o tipo de RSE adotado pelas corporações. Para identificar qual abordagem é realizada pela empresa, verificar as características dos projetos implantados é fundamental. Além disso, deve-se considerar o setor de atuação, as necessidades da comunidade e aquilo que for melhor para o business da corporação (PONTES, 2011).

É relevante frisar que não há parâmetros rígidos na classificação de projetos e iniciativas das organizações em questões sociais genéricas, cadeia de valor e contexto competitivo, pois as empresas são diferentes e possuem objetivos, preocupações sociais e negócios diversos. Uma situação que exemplifica essa afirmação é a prática de redução da emissão de gás carbônico. Para uma corporação do setor bancário, a relevância é baixa, contudo, é um aspecto importante para a cadeia de valor de uma empresa de transporte e estratégico para uma montadora de automóveis (PORTER; KRAMER, 2006).

Desse modo, a escolha da área em que a ação será estabelecida dependerá do negócio da corporação, do local em que se localiza e do propósito almejado. Portanto, para classificar uma ação desenvolvida pela empresa como estratégica será necessário que os impactos causados aos stakeholders afetados pela atividade operacional sejam transformados em métodos para atingir os resultados (PEREIRA et al., 2009).

\section{Comunicação entre empresa e sociedade}

As empresas, além de desenvolverem as práticas de RSE e implementá-las de maneira eficiente, precisam comunicá-las ao público de interesse. Atualmente, os consumidores procuram conhecer muito 
mais do que somente os produtos adquiridos, por isso é relevante que as organizações divulguem as suas ações. A divulgação desses dados não é obrigatória, mas requerida pelos agentes que se relacionam com a corporação. Os meios mais utilizados para expor as informações são a publicidade (propagandas), os relatórios e as páginas web (MONTEIRO, 2010).

Segundo Barros (2008), as principais formas utilizadas de publicar as ações aos stakeholders são através de relatórios e contas anuais, geralmente em papel. No entanto, essa forma de comunicação não é a mais indicada, uma vez que limita o acesso a uma parte interessada específica, além de não ser a mais viável economicamente. São necessárias novas formas de divulgação das ações de responsabilidade social e, dentre elas, destaca-se o uso da internet por meio de websites corporativos. As informações disponibilizadas, geralmente, são compatíveis com aquelas contidas nos documentos físicos.

Segundo Monteiro (2010), essa forma de interação oferece vantagens, como a publicação de grande volume de material rapidamente, o acesso em tempo real, o direcionamento do conteúdo a grupos específicos, a disposição de seções dirigidas a diversos grupos com os quais se relacionam e a criação de links nas páginas web para fornecer dados mais detalhados.

Deve-se considerar a internet por meio de páginas web como um meio importante de divulgação das ações realizadas pelas empresas. Como mostra a pesquisa realizada pelo Instituto Akatu, em 2010, dentre aqueles consumidores que buscam informações sobre a RSE nas organizações, essa forma de divulgação é a mais utilizada. Os motivos para isso são comodidade, rapidez, maior volume de dados, entre outros. Além disso, ela proporciona uma exposição de informações mais profunda e reduz o custo financeiro (BARROS, 2008).

As páginas web são uma forma de exposição das ações que pode atingir um número maior de partes interessadas e proporciona a oportunidade de divulgar uma quantidade maior de questões de forma voluntária (BARROS, 2008). 
No entanto, a utilização de informação disponibilizadas na internet para o estudo da RSE é encontrada em um pequeno número de estudos. Muitos deles são estudos que possuem como objetivo a comparação entre empresas, setores ou países (CALIXTO, 2011; CHEN; BOUVAIN, 2009; FARACHE et al., 2007; FERRAZ; RAFAEL, 2012; FRANÇA et al., 2011; SANTIAGO; GOMES, 2008; WARDERLEY et al., 2008).

Chen e Bouvain (2009), Farache et al. (2007), Wanderley et al. (2008) e Calixto (2011) abordaram a diferença da comunicação da responsabilidade social entre empresas de distintos países e setores. Os três estudos adotaram amostras e métodos distintos, no entanto, aceitaram as hipóteses da influência do país e setor de atuação na comunicação da responsabilidade social. No caso de Calixto (2011), sua conclusão foi que empresas latino-americanas de grande porte situadas no Brasil comunicam mais suas ações de responsabilidade social pela internet, se comparadas às grandes empresas de outros países latinoamericanos (Peru, Chile e Argentina). A mesma autora também ressalta que a divulgação socioambiental pela internet no Brasil é mais frequente em companhias do setor de energia elétrica do que em outros setores, devido à sua regulamentação por órgão específico e obrigação em publicar relatório com informações socioambientais.

Assim como os trabalhos citados anteriormente, França et al. (2011) abordaram a diferença da comunicação da responsabilidade social entre setores e a diferença de comportamento entre empresas que atuam no mesmo setor. Santiago e Gomes (2008) e Ferraz e Rafael (2012) tiveram como foco apenas a diferença entre empresas. Ferraz e Rafael (2012) estudaram as empresas de um nicho do setor de turismo de Portugal e concluíram que ainda é muito deficiente a divulgação de informação de responsabilidade social na maioria das organizações estudadas.

\section{Metodologia}

O objetivo da pesquisa consistiu em descrever as ações de responsabilidade social das empresas que são referências nessa área, 
nos seus respectivos setores, e identificar se as ações realizadas por elas podem ser classificadas como estratégicas ou responsivas. Para este estudo, das 21 empresas modelo em sustentabilidade do Guia Exame de 2012, foram escolhidas aleatoriamente, duas empresas do setor de cosméticos (Natura e O Boticário) e duas do setor de energia (CPFL Energia e Elektro). Esses setores foram escolhidos pelos grandes impactos que causam nas suas operações, notadamente na biodiversidade, recursos hídricos, energia, entre outros. A escolha dessas quatro empresas permitiu observar a diversidade das ações de responsabilidade social dentro do mesmo setor e entre setores.

O Guia Exame de Sustentabilidade é publicado anualmente pela revista Exame e destaca as empresas modelo em sustentabilidade no Brasil. Para participar, as empresas devem preencher um questionário. As respostas são submetidas ao Centro de Estudos em Sustentabilidade da Fundação Getúlio Vargas (GVCes). O questionário é composto por aproximadamente 140 perguntas, agrupadas em quatro partes. $\mathrm{Na}$ primeira, são abordadas questões sobre compromissos, transparência e governança corporativa. As demais tratam das dimensões econômicofinanceira, social e ambiental da sustentabilidade empresarial. Além de responderem ao questionário, as empresas são convidadas a relatar iniciativas recentes relacionadas à sua estratégia de sustentabilidade. Após avaliação, um grupo de empresas selecionadas se submete a um conselho deliberativo, formado por especialistas, que elege as empresas modelo, sem ranking de classificação.

A metodologia da pesquisa seguiu o modelo indutivo, descritivoanalítico, qualitativo. O modelo indutivo, segundo Kauark et al. (2010), é uma atividade mental por meio da qual se realiza um encadeamento de ideias que auxilia na argumentação, tendo como ponto de partida dados particulares para se inferir uma verdade geral ou universal. $O$ método descritivo-analítico, conforme enunciado por Marconi e Lakatus (2008), tem como característica a decomposição do todo em partes e, em seguida, a realização da análise das relações entre elas. Por outro lado, o método qualitativo é aquele que trabalha com dados descritivos, pois possui o intuito de compreender os significados e as situações 
apresentadas (MARCONI; LAKATUS 2008). E utilizou-se o método da análise de conteúdo para coletar as informações divulgadas sobre RSE na internet (FARACHE et al., 2007). Esse método, segundo Barros (2008), fundamenta-se na classificação das informações divulgadas nas páginas web em categorias de elementos, possibilitando a coleta de dados do que se pretende analisar.

No intuito de alcançar o objetivo proposto, desenvolveu-se uma lista de indicadores baseados principalmente nos estudos realizados por Calixto (2011) e Ferraz e Rafael (2012). O primeiro estudo utilizou as diretrizes voluntárias da Global Reporting Initiative, revisão bibliográfica e verificação preliminar dos relatórios das organizações como escopo para desenvolver os indicadores a serem analisados nas paginas web das empresas estudadas. Já o segundo estudo utilizou o modelo RIWAN (Responsible Identity Web Analysis Method) e indicadores de outros estudos com objetivos similares. Foram escolhidos para participar deste estudo os indicadores pertinentes aos dois setores estudados que permitissem a análise proposta de classificação em "estratégica" ou "responsiva" das ações praticadas e comunicadas pelas empresas estudadas.

Os indicadores escolhidos foram verificados nas páginas web das empresas estudadas, com o auxílio da ferramenta busca de palavraschave. Todos os documentos encontrados com uma palavra-chave que identificasse o indicador foram lidos e analisados, e em seguida, classificado em "estratégico" ou "responsivo", considerando a revisão bibliográfica, as características das ações e as características da empresa e do setor. As informações foram coletadas nos links oferecidos pelas empresas e por meio dos downloads de relatórios de sustentabilidade, conforme a disponibilidade de materiais de cada organização. Os relatórios analisados foram dos anos de 2011 e 2012.

Com o intuito de facilitar a análise de conteúdo, e devido às características dos setores estudados, os indicadores foram agrupados em: ações no âmbito social e ações no âmbito ambiental. A relação dos indicadores por âmbito é apresentada na Tabela I. 
Tabela 1 - Tabela de Indicadores

\begin{tabular}{ll}
\hline \multicolumn{1}{c}{ Âmbito Social } & \multicolumn{1}{c}{ Âmbito Ambiental } \\
\hline - Doações realizadas pela empresa. & - Política de compras / avaliação \\
de fornecedores.
\end{tabular}

Fonte: Elaborado pelas autoras (2013).

A coleta das informações realizou-se através de visitas nas páginas web das empresas escolhidas, no período de 29 de maio de 2013 a 03 de junho de 2013. As páginas web das empresas estudadas foram visitadas inúmeras vezes durante o período da coleta de dados.

Os resultados foram apresentados por setor e, posteriormente, apresentou-se uma tabela com o resumo das ações de âmbito social e ambiental, e sua classificação em ação responsiva ou estratégica, o que possibilitou atingir o objetivo proposto do estudo.

\section{Resultados}

\subsection{Características das duas empresas do setor de cosméticos}

A Natura tem como visão de futuro priorizar a qualidade dos produtos e serviços, e manter uma boa relação com todos os envolvidos 
com o negócio da organização. Pretende ser uma marca de expressão mundial identificada com a comunidade e comprometida com a construção de um mundo melhor por meio da relação consigo mesmo, com os outros e com o meio ambiente.

Para o grupo O Boticário, a visão estabelecida é comprometerse em longo prazo com os desafios sociais e ambientais, orientando o negócio para a longevidade da organização e contribuindo com a sociedade e o meio ambiente.

\subsection{Resultados do setor de cosméticos}

O primeiro indicador avaliado foi "política de compra". Esse ponto revelou a preocupação das duas empresas com as demais partes envolvidas no negócio em que atuam. A Natura possui um método de avaliação de fornecedores denominado Qlicar. Ele foi criado para garantir a qualidade na aquisição de insumos, produtos e serviços de terceiros. A empresa identifica a qualidade dos parceiros através de um processo de acompanhamento e certificação daqueles que atendem aos princípios da sustentabilidade. A avaliação e o controle desse processo são realizados através de um sistema de pontuação Score Card. Do mesmo modo, o grupo O Boticário preocupa-se com a gestão de toda a cadeia de valor da empresa e utiliza o Processo de Avaliação de Desempenho de Fornecedores (PADF) e o Processo de Avaliação de Desempenho de Fornecedores de Serviço (PADFS) com o intuito de desenvolver e realizar o reconhecimento formal das empresas de melhor desempenho. Em 2011, os critérios de sustentabilidade para esse grupo acresceramse da responsabilidade pelo produto, das relações humanas e ações de ecoeficiência. O grupo contou com um questionário de autoavaliação, disponibilizado no ambiente on-line, e a ferramenta Assessment of Excellence in Procurement (AEP), que abrangeu os processos de compra do grupo. Os contratos de fornecimentos possuem cláusulas para atender aos quesitos legais e outros definidos pelo grupo.

Quanto ao indicador "reciclagem de materiais", averiguou-se que as duas empresas possuem ações. A Natura, para estimular a 
reciclagem, possui o Movimento Natura. Nele, os consultores recolhem as embalagens utilizadas pelos consumidores em alguns locais estabelecidos. Além disso, a empresa trabalha com a tecnologia do plástico verde em refis e a utilização de embalagens $100 \%$ recicláveis na linha Natura Ekos. Já o grupo O Boticário adota como principal medida um canal para devolução da embalagem pós-consumo, que é reciclada e aproveitada em novos ciclos de produção (em 2010, todas as lojas da marca foram contempladas). A empresa também promove a conscientização da população sobre a coleta seletiva, a capacitação e o acompanhamento dos catadores de material reciclável.

Outro indicador analisado diz respeito às informações descritivas sobre o uso racional da água, já que a escassez desse recurso representa riscos ao planeta. Nesse quesito, a Natura procura aferir o consumo interno de água e, para tanto, conta com o programa Pegada Hídrica, que quantifica a água utilizada e poluída no processo produtivo. Em 2011 a empresa conseguiu uma redução no consumo de $4,7 \%$ por unidade produzida, devido ao reaproveitamento e tratamento da água utilizada nas operações. Já o grupo O Boticário realiza a captação do recurso por meio da rede pública de abastecimento. Em 2011, conseguiu uma redução no consumo de água de $6 \%$, devido ao processo de reutilização da água.

Outro indicador analisado foi "energia". Observamos que as duas empresas economizam, devido às melhorias de conservação e eficiência. A Natura obteve, em 2011, redução no consumo de $12 \%$, devido a processos de melhoria de equipamentos e eliminação de perdas. Da mesma forma, o grupo O Boticário realizou várias medidas que auxiliaram na redução de 34\% no consumo, pois em 2007 a empresa passou a utilizar luminárias de LED e essa medida proporcionou a redução de $68 \%$ no consumo. O grupo também utilizou letreiros de LED, circuitos de iluminação individualizados, além da técnica de emulsificação de baixa energia para o processo de produção de emulsões como cremes e loções, em 2010. Desse modo, o processo ajudou na diminuição do tempo necessário para a produção e, consequentemente, na redução de energia. 
Outro indicador averiguado foi "desempenho ambiental". Nesse ponto, buscou-se saber da existência de estratégias para recuperação ou reabilitação de áreas degradadas. A Natura realiza a recuperação florestal de áreas degradadas para compensar a emissão de gases do efeito estufa (GEEs) que foram lançados no ambiente. Entre as ações desenvolvidas pela empresa, estão a recuperação de 200 hectares de áreas degradadas no entorno do Parque Nacional de Emas e Parque Estadual das Nascentes do Rio Taquari. Outras medidas adotadas são os projetos Carbono Socioambiental do Xingu, Carbono Florestal, entre outros. O grupo $\mathrm{O}$ Boticário trabalha voltado para várias estratégias de conservação da Mata Nativa e possui a Fundação Grupo Boticário de Proteção à Natureza, que realiza projetos de proteção à fauna, além de ações como o Bio\&Clima-Lagamar e Oásis.

Sobre o indicador "comprometimento com redução de gases sobre o clima", a Natura reduziu $25,4 \%$ das emissões no período de 2006 a 2011. O principal programa da empresa é o Carbono Neutro, que busca a contínua redução das emissões dos gases, pois tem como meta ser uma organização de carbono neutro. Já o grupo O Boticário utiliza formas de mitigar emissões, como o incentivo ao transporte fretado e à carona solidária; gerador com gás natural, em substituição ao diesel; e workshop para o engajamento de fornecedores, com o propósito de reduzir as emissões na logística de produtos e matérias-primas.

Outro indicador relevante foi "gestão de resíduos". A Natura desenvolve um programa próprio de gestão de resíduos, com o intuito de transformá-los em novos negócios. O gerenciamento dos resíduos segue como diretriz a redução do volume gerado e a ampliação da reciclagem. Em 2011, a redução dos resíduos foi de $23 \mathrm{~g}$ para $20 \mathrm{~g}$ por unidade. Uma das principais iniciativas do grupo $\mathrm{O}$ Boticário veio com a temática do Programa Freepacking, em que caixas e embalagens dos produtos foram reutilizadas, assim, o total de material reutilizado foi de 2.142 t em 2011.

No que se refere ao desempenho social, o primeiro indicador investigado foi "doação". A Natura mencionou no relatório que não 
realiza doações a candidatos ou partidos políticos e não menciona doações específicas - apenas cita em um quesito de desempenho econômico "doações e outros investimentos na comunidade". Já o grupo O Boticário apresentou informações do investimento social privado, em 2011, em que a Fundação Grupo Boticário realizou doações no valor de $\mathrm{R} \$$ 7.739.215,00 e o Instituto Grupo Boticário doou R\$ 3.037.710,00. Contudo, a empresa não descreveu para quais instituições os respectivos valores foram destinados.

Outro indicador analisado foi "relação com o governo". A Natura tem um relacionamento com o governo que valoriza a formulação de políticas públicas e a participação em discussões, o que é relevante para a empresa e para a sociedade. O grupo O Boticário menciona apenas que atuou junto com o governo em projetos e políticas públicas.

Outro ponto pesquisado foram as iniciativas que as empresas realizam junto à comunidade. A Natura está engajada em vários projetos direcionados às comunidades no entorno de suas fábricas e centros de distribuição. Esses projetos se relacionam com a contratação de jovens aprendizes e público operacional, além de terceiros e prestadores de serviço residentes na proximidade das instalações. A empresa fornece produtos para cursos profissionalizantes gratuitos, como cabeleireiro e maquiador da Faetec, e realiza ações em comunidades do Rio de Janeiro, onde tem escritório comercial. As ações nessas localidades procuram incentivar e apoiar as pessoas que desejam ser consultor/ consultora da empresa e apresenta um modelo de produção que envolve o relacionamento com comunidades fornecedoras que se caracterizam como cooperativas e associações, majoritariamente na Região Amazônica. Além disso, a empresa apoia o fortalecimento da cultura, o fortalecimento institucional e a expansão da consciência do desenvolvimento sustentável. Outros projetos apoiados pela Natura são: Natura Musical, Mata Atlântica é Aqui e Floresta Faz a Diferença. O grupo O Boticário tem como principais iniciativas a Fundação Grupo O Boticário de proteção e conservação da biodiversidade, a formação profissional para o desenvolvimento local a partir do incentivo à geração de emprego e renda, curso gratuito de operador de empilhadeira e a 
realização do curso Operador de Processo de Fabricação. Além disso, destina recursos para: espaços educativos e culturais, as Estações Natureza, que são exposições interativas sobre a natureza brasileira; fornecimento de materiais para as escolas inserirem a temática ambiental; e o programa Dê a Mão para o Futuro, que direciona recursos para a gestão de espaços educativos e culturais em parceria com outras instituições.

Sobre o indicador "atividade esportiva", não foram encontradas informações nos relatórios das duas empresas investigadas.

Outro indicador verificado foi "desempenho social das duas organizações e a capacitação técnica". Nele, observou-se que a Natura desenvolve programas de formação e desenvolvimento de liderança, educação para a inovação, capacitação para gerentes de relacionamento e formação para estagiários. Já o grupo O Boticário realiza análise de desempenho das competências pessoais e técnicas. Outra ação do grupo é a Universidade Corporativa, que promove programas de qualificação de trainees, estagiários e jovens aprendizes, além do projeto Times de Alto Desempenho, que tem por objetivo proporcionar autonomia, capacitação e informação aos colaboradores.

Quanto ao indicador "consumo responsável, observou-se que as duas empresas realizam ações. A Natura acredita que tem o compromisso de informar e contribuir para a ampliação da consciência dos consumidores através das mídias sociais e o grupo O Boticário acredita que, ao possuir como ideais a gestão de resíduos de embalagens e a redução do consumo de água e energia, está engajado na busca interna pelo consumo responsável, com o objetivo de transmitir esses valores para a comunidade do entorno.

Por fim, averiguou-se o indicador "investimento em educação". A Natura criou um instituto para potencializar esforços a fim de proporcionar melhorias no ensino público. A empresa, em parceria com o Ministério da Educação, transformou o projeto Trilhas em política pública. Essa ação visa incentivar a leitura, a escrita e a oralidade para estudantes de 6 anos de idade. A parceria com o Ministério da Educação vai possibilitar 
a expansão do projeto para três mil municípios do país. Os recursos do Instituto Natura provêem da arrecadação de uma linha especial de produtos não cosméticos, "Crer para Ver". O grupo O Boticário também possui políticas de educação. A empresa destina parte de suas receitas para projetos de conservação, ações culturais e educativas. Além disso, trabalha com o projeto Estação Natureza, cujo objetivo é sensibilizar a população sobre a questão ambiental, e ainda realiza atendimento em escolas, do nível infantil ao ensino médio, fornecendo materiais necessários para a inserção da temática ambiental.

Em face desses resultados, apresenta-se uma tabela resumo das ações de responsabilidade social realizadas pelas empresas Natura e $\mathrm{O}$ Boticário, que compõem o setor de cosméticos.

Tabela 2 - Tabela resumo das ações de responsabilidade social do setor de cosméticos

\begin{tabular}{lcc}
\hline \multicolumn{2}{l}{ Identificação da Responsabilidade Social Corporativa } & \\
\hline Desempenho Ambiental & Natura & O Boticário \\
\hline Política de compras & Estratégica & Estratégica \\
$\begin{array}{l}\text { Reciclagem de material } \\
\text { Informações descritivas sobre o uso } \\
\text { racional da água }\end{array}$ & Estratégica & Estratégica \\
$\begin{array}{l}\text { Energia economizada devido a melhorias } \\
\text { em conservação e eficiência }\end{array}$ & Estratégica & Estratégica \\
$\begin{array}{l}\text { Estratégias para recuperação ou } \\
\text { reabilitação de áreas degradadas }\end{array}$ & Estratégica & Estratégica \\
$\begin{array}{l}\text { Compromisso com a redução dos efeitos de } \\
\text { emissões de gases sobre o clima }\end{array}$ & Estratégica & Estratégica \\
Gestão de resíduos & Estratégica & Estratégica \\
$\begin{array}{l}\text { Desempenho social } \\
\text { Doações }\end{array}$ & Estratégica & Estratégica \\
$\begin{array}{l}\text { Relações com o governo } \\
\text { Iniciativas sociais junto à comunidade }\end{array}$ & - ------------ & \\
$\begin{array}{l}\text { Atividades esportivas } \\
\text { Capacitação técnica } \\
\text { Consumo responsável } \\
\text { Investimentos em educação }\end{array}$ & Estratégica & Responsiva \\
\hline
\end{tabular}

Fonte: Elaborado pelas autoras, 2013. 


\subsection{Características das duas empresas do setor de energia}

A análise no setor de energia foi realizada tendo em vista as empresas Companhia Paulista Força e Luz (CPFL Energia) e Elektro. A primeira adota como visão de futuro a importância da energia ao bemestar das pessoas e ao desenvolvimento da sociedade, e a produção sustentável desse recurso. A política de sustentabilidade leva em conta a responsabilidade nos processos de gestão dos negócios por meio do gerenciamento dos impactos econômicos, sociais e ambientais. A Elektro é comprometida com a qualidade dos serviços, a melhoria e inovação dos processos e a forma de gestão, a fim de satisfazer as partes interessadas, e almeja ser a distribuidora de energia mais admirada do país.

\subsection{Resultados setor de energia}

A coleta de informações das organizações que compõem a amostra nesse setor iniciou-se com a política de compra adotada. A CPFL Energia exige de fornecedores homologados as documentações expedidas por autoridades ambientais nas esferas estadual, federal e municipal. Essa exigência faz parte do processo de compra firmado. Há um programa de avaliação dos fornecedores críticos, isto é, aqueles que impactam nos processos internos. Além disso, são oferecidos prêmios como o CPFL Mais Valor, que avalia a performance dos fornecedores em quesitos como qualidade, prazo, segurança, responsabilidade social e respeito ao meio ambiente. A Elektro, do mesmo modo, apresenta uma política de compra com critérios rigorosos na seleção e contratação dos fornecedores. A empresa avalia o processo de fabricação e entrega, além de realizar visitas às unidades fabris. São contratados no mínimo dois fornecedores críticos para a continuidade das operações. Assim como a CPFL, a Elektro realiza o Prêmio Fornecedor Elektro, que busca disseminar boas práticas e estimular a melhoria dos processos tanto para a organização quanto para os parceiros. A empresa não adota critérios específicos para a contratação de parceiros locais, mas compras com valor até $R \$ 2.000,00$ são realizadas em escritórios nas próprias regiões. 
Com relação ao indicador "reciclagem de materiais", observouse que as duas empresas possuem medidas. A CPFL apresenta a logística reversa dos materiais inservíveis retirados da rede elétrica, encaminhando-os para a reciclagem, e efetua a triagem daqueles retirados da rede de distribuição. Outra mobilização da organização refere-se à coleta seletiva de materiais realizada na sede, em Campinas, também destinados à reutilização. A Elektro tem políticas semelhantes às da CPFL. Ela envia para o processo de reciclagem as sucatas, lâmpadas e outros materiais gerados nas operações. A empresa trabalha com o programa Recicla Elektro, que tem por objetivo organizar o processo de coleta seletiva de materiais e, em contrapartida, oferece uma redução no valor das contas de energia elétrica, principalmente para a população de baixa renda.

O terceiro indicador analisado refere-se às "informações descritivas sobre o uso racional da água”. Na CPFL, o consumo de água ocorre para as atividades administrativas e não apresenta perda de água durante a utilização. No entanto, ela desenvolve vários programas para uso e conservação dos recursos hídricos, como curso de formação para educadores (Navegando nas Águas do Conhecimento), programas de educação ambiental, além de realizar a reutilização das águas pluviais. Já a Elektro reduziu em 4,5\% o consumo de água em 2011 em relação a 2010, devido às campanhas de conscientização ambiental e medidas como o uso de bacias sanitárias com caixas acopladas, torneiras temporizadas e poços artesianos para irrigação das áreas externas.

Outro indicador verificado refere-se à "energia economizada devido a melhorias em conservação e eficiência". Observou-se que ambas as empresas apresentam medidas nessa área. A CPFL conta com o Programa de Eficiência Energética, iniciado em 1998. As distribuidoras que compõem o grupo por meio desse projeto incentivam a redução e o uso racional do consumo de energia elétrica nas comunidades, iniciativa privada e órgãos públicos. A Elektro, por sua vez, reduz o consumo através de medidas como o desligamento automático de lâmpadas depois das $19 \mathrm{~h}$ e destina recursos para projetos que visam à educação para o consumo racional e eficiente de energia. 
Quanto ao indicador que analisa "medidas de recuperação ou reabilitação de áreas degradadas", observou-se que as empresas em estudo apresentaram inúmeras ações. A Elektro possui o programa Meninos Ecológicos para formar monitores ambientais que divulguem conceitos de sustentabilidade. As mudas produzidas nesse projeto são utilizadas em campanhas internas e doadas a prefeituras e escolas dos municípios das áreas de concessão, para a recuperação destas e arborização urbana. A empresa possui o Programa de Gestão Ambiental, que atua no gerenciamento dos programas ambientais compensatórios. Estes visam minimizar os impactos provocados pelas operações da empresa, através de reflorestamento, educação ambiental, entre outras medidas. Entretanto, a legislação exige a compensação ambiental por meio do Termo de Compromisso de Recuperação Ambiental (TCRAs), assim, no ano de 2010, a empresa propôs à Cetesb o cumprimento de diversos TCRAs de forma unificada por meio de plantio de mudas em locais estratégicos. São programas ambientais adotados: Ambiental para Construção, Educação Ambiental, Monitoramento de Fauna, Florestal, Comunicação Social, Recuperação das Áreas Degradadas e Gestão ambiental. A empresa busca, também, engajar os colaboradores em ações de preservação ambiental. Do mesmo modo, a CPFL Energia possui várias atividades de reflorestamento por meio da assinatura de TCRAs e programas socioambientais que abrangem recuperação de locais degradados, educação ambiental, reposição florestal de espécies pertencentes ao bioma dominante, replantio nas áreas de preservação permanente e preservação da biodiversidade. Além disso, conta com programas como o Programa de Monitoramento e Resgate de Flora, Semana do Meio Ambiente, entre outros.

No indicador "comprometimento com a redução dos gases sobre o clima”, observou-se que as duas empresas em análise cumprem esse quesito. A Elektro monitora as emissões de gases dos veículos e dos geradores das subestações. E, caso seja necessário, aplica o tratamento de não conformidade. A empresa engloba o desenvolvimento de um projeto de propulsão para veículos elétricos de transporte de passageiros que não emite poluente. A CPFL, por sua vez, adota, desde 2007, o 
compromisso com gestão dos gases de efeito estufa (GEEs). Para tanto, elabora um inventário de emissões de GEEs. Porém, a empresa não desenvolveu nenhuma iniciativa de redução mensurável desses gases que ocasionasse uma diminuição significativa. A principal forma utilizada é a de compensação voluntária e mecanismos de desenvolvimento limpos.

Outro indicador relevante investigado foi "gestão de resíduos". A Elektro possui um programa que tem por objetivo eliminar ou reduzir desperdícios e contribuir para a destinação correta de rejeitos. Os resíduos produzidos são tratados de acordo com os padrões exigidos pela legislação. A preocupação com essa variável é compartilhada pela empresa CPFL, que destina os resíduos somente para unidades licenciadas pelos órgãos ambientais, mediante emissão de certificado de destinação final. O programa de gestão de resíduos identifica e classifica os rejeitos e estabelece as normas de descarte, destinação e armazenamento.

No tocante ao desempenho social, o indicador "doação" não apresentou nenhum resultado para a CPFL. Já a Elektro apenas menciona o recebimento de doações não vinculadas a qualquer retorno em favor dos repassadores de recursos. Os recursos recebidos são destinados a investimentos no serviço de distribuição de energia elétrica.

Também foi averiguado o indicador "relação com o governo", relevante para as empresas, devido ao caráter estratégico do setor para o país. A CPFL apresenta uma ampla estrutura para atender e dialogar com poder público. O relacionamento com os órgãos é essencial para a empresa acompanhar e participar do processo de planejamento energético do país. Já a empresa Elektro possui uma estrita relação com o governo e apresenta medidas como tarifas especiais, participação em programas do governo federal (como o projeto Luz para Todos) e outros que visem à expansão das redes de média e baixa tensão para universalização do acesso a esse recurso.

Em relação à análise do indicador investimento social junto à comunidade se observa que as empresas desenvolvem várias ações. A 
Elektro apresenta diversos projetos em áreas, como: esporte, educação, meio ambiente e cultura. Dentre esses projetos, destaca-se: Escola inclusiva, Instituto Elektro na Comunidade, Escola de Eletricistas, Energia em Cena, Esporte Energia, Energia Musical, Elektro nas Escolas, Recicla Elektro, Baixa Renda, entre outros. Do mesmo modo, a CPFL apoia 23 projetos na área de educação, cultura e esporte que visam contribuir com o desenvolvimento sustentável dos municípios das áreas do empreendimento, entretanto, constatou-se que a maior parte dos projetos estão atrelados as práticas de conservação do meio ambiente.

No indicador esporte observou-se que a empresa CPFL recebeu em 2010 o prêmio Empresário Amigo do Esporte do Ministério do Esporte, devido ao apoio oferecido aos projetos esportivos. Contudo, não há no relatório a descrição dos projetos apoiados. Já o instituto Elektro, desde 2010, promove projetos por meio das Leis de Incentivos Fiscais ao esporte e dentre os seus projetos destacam-se: O Kimono de Ouro e Esporte Energia.

Com relação ao indicador "capacitação técnica", constatouse que tanto a Elektro quanto a CPFL realizam atividades. A Elektro possui programas voltados estritamente ao negócio de atuação, pois as ações estão direcionadas à segurança dos colaboradores, a fim de prevenir acidentes de trabalhos. Além disso, a empresa possui medidas relativas ao comportamento seguro dos meios de transporte, já que trabalha com o processo de leitura e entrega simultânea de conta aos consumidores. São projetos da companhia: Programa Comportamento pela Vida, Observação de Segurança, Segurança em Foco, Avaliação de Condutores e treinamentos de direção segura. Os projetos visados pela CPFL direcionam os esforços para o desenvolvimento de habilidades e atitudes dos funcionários para o desempenho das rotinas de trabalho por meio da Universidade Corporativa.

Quanto ao consumo responsável, as empresas analisadas promovem iniciativas de maneira semelhante, visando à orientação para o uso racional e eficiente de energia elétrica. Destaca-se na Elektro a 
campanha lançada no ano de 2011, em parceria com o grupo Ciência em Show, sob o título "Consciência é mais energia".

No que diz respeito ao indicador "investimento na educação", percebeu-se que as duas empresas possuem ações. A CPFL apoia o Compromisso Campinas pela Educação, que surgiu a partir do movimento nacional Todos pela Educação, e aplica recursos voltados para a educação ambiental. Em sintonia com o Pacto Global, a Elektro investe na educação básica por meio de projetos como o Cozinha Show e o Instituto Elektro na Comunidade, criado em 2011.

Em face desses resultados, apresenta-se uma tabela resumo das ações de responsabilidade social realizadas pelas empresas CPFL Energia e Elektro, que compõem o setor de energia.

Tabela 3 - Tabela resumo das ações de responsabilidade social do setor de energia

\begin{tabular}{lll}
\hline Identificação da Responsabilidade Social Corporativa & & \\
\hline Desempenho Ambiental & CPFL Energia & Elektro \\
\hline Política de compras & Estratégica & Estratégica \\
$\begin{array}{l}\text { Reciclagem de material } \\
\text { Informações descritivas sobre o uso racional da água }\end{array}$ & $\begin{array}{l}\text { Estratégica } \\
\text { Energia economizada devido a melhorias em }\end{array}$ & Estratégica \\
$\begin{array}{l}\text { Enesponsiva } \\
\text { conservação e eficiência }\end{array}$ & Estratégica & Estratégica \\
$\begin{array}{l}\text { Estratégias para recuperação ou reabilitação de áreas } \\
\text { degradadas }\end{array}$ & Estratégica & Estratégica \\
$\begin{array}{l}\text { Compromisso com a redução dos efeitos de emissões } \\
\text { de gases sobre o clima }\end{array}$ & Estratégica & Estratégica \\
Gestão de resíduos & Estratégica & Estratégica \\
$\begin{array}{l}\text { Desempenho social } \\
\text { Doações }\end{array}$ & & \\
Relações com o governo & - ------------ & Estratégica \\
Iniciativas sociais junto à comunidade & Estratégica & Estratégica \\
Atividades esportivas & Estratégica & Estratégica \\
Capacitação técnica & Estratégica & Estratégica \\
Consumo responsável & Estratégica & Estratégica \\
Investimentos em educação & Estratégica & Estratégica \\
\hline
\end{tabular}

Fonte: Elaborado pelas autoras (2013). 


\section{Discussões}

Constata-se que as quatro empresas analisadas realizam práticas de RSE tanto para atender às próprias necessidades como as da comunidade e de todas as partes interessadas com as quais se relacionam com o intuito de alcançar as metas estabelecidas.

Os indicadores investigados apresentam, em sua maioria, caráter estratégico dominante quando comparados com o setor de atuação da empresa, a visão de futuro e os beneficiários das medidas desenvolvidas. Não obstante, considera-se que, dentro de uma mesma categoria de elementos, analisados revelam projetos de natureza tanto estratégica quanto responsiva.

No que concerne às iniciativas realizadas junto à comunidade, observa-se que tanto a empresa Natura como o grupo O Boticário possuem projetos que se encaixam nas duas definições propostas - de responsabilidade social estratégica e responsiva. Por exemplo, o projeto Natura Musical apoia a cultura brasileira. De maneira geral, a cultura não está relacionada com o negócio principal e, ao identificar a abrangência deste, verifica-se que o projeto em questão possui ações que contemplam 17 estados, ou seja, ele não beneficia apenas a comunidade no entorno das fábricas e o centro de distribuição. Desse modo, conclui-se que, com essa ação de responsabilidade social, a empresa pretende consolidar a imagem de boa cidadã em relação às atividades culturais.

Ao mesmo tempo em que a Natura Musical e outros projetos que abrangem também o grupo O Boticário apresentam caráter responsivo, há programas que atendem às características de RSE estratégica, como a contratação de jovens da comunidade no entorno do empreendimento para exercer funções nas corporações e o oferecimento de curso de operador de empilhadeira e operador de processo de fabricação. Assim, do ponto de vista físico, esses programas auxiliam na capacitação de pessoas da comunidade e ao mesmo tempo beneficiam as empresas, tendo em vista que esses treinamentos oferecidos são úteis para as operações das organizações. 
Os estudos realizados por Porter e Kramer (2006) mostram que a Responsabilidade Social Corporativa Responsiva caracteriza-se pela utilização de boas práticas por parte da empresa e busca a mitigação dos impactos originários da cadeia valor. Desse modo, nota-se que apesar de contribuir para a melhoria das relações entre os grupos de interesse, as atividades com estas características não influenciam no contexto competitivo. Ao contrário, as empresas que utilizam as ações de caráter estratégico possuem vantagens, pois esta visa obter medidas benéficas tanto para a sociedade quanto para organização. Poter e Kramer (2006) afirmam em seus estudos que quanto mais ligada ao negócio da empresa for à prática de RSE melhor serão os resultados obtidos.

Outro dado importante que se percebe é que as empresas modelo em sustentabilidade possuem projetos e medidas ligadas ao negócio em que atuam, pois em alguns quesitos analisados as providências se iniciam para cumprir a determinação legal e se estendem como forma de alcançar benefícios para a sociedade e para a empresa. Isso se evidencia, por exemplo, quanto à gestão de resíduos. As empresas, desde 2010, precisam atender às exigências da Política Nacional de Resíduos Sólidos. Entretanto, há várias medidas utilizadas por elas que superam as expectativas, principalmente levando-se em consideração os investimentos em inovação tecnológica.

Dessa forma, verifica-se que o programa de gestão de resíduos desenvolvido pela Natura no contexto da reciclagem, por exemplo, é formado por diversas medidas inovadoras, pois a empresa desenvolve a Linha Ekos com produtos biodegradáveis e a utilização de vidros e embalagens $100 \%$ recicláveis. Em toda a linha de perfumaria, o álcool tradicional foi substituído pela versão orgânica, proveniente da cana de açúcar, porém, isso não altera os atributos nem a qualidade dos produtos. Desse modo, constata-se que as ações caracterizamse como estratégicas, por estarem intimamente ligadas ao negócio da organização e serem uma forma de redução de custos que permite o aumento de competitividade e benefícios para a comunidade. 
Observa-se que o setor de cosméticos apresenta práticas de responsabilidade social em quantidades superiores ao do setor de energia em indicadores como reciclagem de materiais, uso racional de água e energia economizada. Isso ocorre porque esses indicadores estão mais intrinsecamente ligados com os negócios desenvolvidos nesse setor. Porém, o setor de energia conta com mais providências no indicador "recuperação ou reabilitação de áreas degradadas", pois a produção de energia no país gera grandes impactos, como inundações de grandes áreas, perda da biodiversidade, deslocamento da população das regiões alagadas, entre outros. Logo, ações que priorizam a conservação e recuperação da vegetação nativa são mais evidentes.

Nota-se que em um mesmo setor há diferenças entre a prioridade de cada organização quanto aos critérios analisados. No setor de cosméticos, tanto a Natura quanto o grupo O Boticário realizam ações de reciclagem de materiais. Contudo, percebe-se que este tem o foco na logística reversa dos materiais e no apoio à coleta e capacitação dos profissionais de reciclagem. Ainda que a Natura também realize o recolhimento de embalagens, o reaproveitamento dos materiais está fortemente atrelado ao desenvolvimento da tecnologia verde, que abrange o uso do plástico verde, proveniente do etanol, nas embalagens de refis, a substituição do álcool tradicional pelo orgânico na linha de perfumaria, entre outras medidas.

Outra evidência de diferença entre empresas de um mesmo setor verifica-se entre a CPFL Energia e a Elektro, pois em relação às iniciativas junto à comunidade, a primeira possui uma maior quantidade de projetos no âmbito ambiental relacionando educação, cultura e esporte, apesar de apoiar ações nas áreas citadas. A Elektro, por sua vez, possui programas ambientais, sociais, culturais e educacionais de forma mais abrangente. É notório que as ações de âmbito ambiental e social praticadas pelas organizações de ambos os setores estudados visam reduzir os impactos gerados pelas operações ao longo de toda a cadeia de valor. 
Os resultados revelam que a classificação de ações, considerando o aspecto estratégico ou responsivo, dentro de um mesmo indicador pode variar, a depender da abrangência e finalidade do programa desenvolvido pela organização. Os investimentos do setor de cosméticos em educação, desse modo, foram classificados como responsivo. Esses resultados confirmam o que defendem Porter e Kramer (2006): a aplicação dos recursos da Natura nesse quesito não está relacionada ao business da empresa nem está restrito a beneficiar a comunidade no entorno das unidades fabris e de distribuição. Da mesma forma ocorre com os investimentos do grupo $\mathrm{O}$ Boticário em projetos como a Estação Natureza, com sede em São Paulo-SP e Corumbá-MS. Como em Corumbá não há uma unidade fabril ou centro de distribuição, esse projeto pode ser descrito como uma ação responsiva. Já na cidade de São Paulo, essa medida pode apresentar um caráter estratégico, porque há um escritório no local.

É importante ressaltar a diferença no foco estabelecido pelas empresas do setor de energia no tocante ao indicador "capacitação técnica", classificado como estratégico. Apesar de classificado como estratégico, o estudo evidencia que a capacitação oferecida pela Elektro aos seus colaboradores está diretamente ligada ao negócio da empresa, visto que ela se preocupa com segurança no trabalho e direção defensiva. Já a CPFL, apesar de possuir ações voltadas na mesma área, os projetos visam desenvolver habilidades dos colaboradores. Embora o foco dessa empresa seja diferente da Elektro, ainda pode ser considerado estratégico, porque prioriza uma boa relação com os funcionários e busca a eficiência, critérios considerados importantes para qualquer organização que almeje alcançar reconhecimento no mercado.

Com efeito, as iniciativas junto à comunidade desenvolvidas pelo setor de energia são elencadas como estratégicas porque abrangem programas de conservação dos recursos ambientais intimamente vinculados ao business das empresas e outros projetos em educação, cultura e esporte que se distanciam de negócio, porém, beneficiam a comunidade no entorno da área de atuação. Estes também são classificados como estratégicos. 
Por fim, em virtude dos aspectos analisados, observa-se que as medidas de responsabilidade social adotadas pelas empresas dos setores de cosméticos e energia possuem o caráter estratégico, o que é importante para as companhias manterem uma vantagem competitiva em relação à concorrência e, assim, permanecerem no mercado.

\section{Conclusão}

O objetivo do presente trabalho foi descrever as ações de responsabilidade social das empresas referências nessa área, nos respectivos setores, e identificar se as ações realizadas por elas podem ser classificadas como estratégicas ou responsivas, utilizando para isso, principalmente, as afirmativas de Porter e Kramer (2006).

Verifica-se que a responsabilidade social está substancialmente presente nas organizações, pois, no contexto atual, as empresas são cobradas pelas obrigações nos aspectos econômicos, sociais e ambientais. No entanto, essa prática deve estar atrelada ao negócio principal, ao setor de atuação e à comunidade envolvida com as corporações, caracterizando a natureza estratégica da responsabilidade social, conforme as afirmativas de Porter e Kramer (2006). Isso porque as ações reveladas de caráter responsivo, apesar de realizarem boas práticas cidadãs, possuem como foco práticas genéricas e filantrópicas que não oferecem o benefício mútuo para empresa e comunidade.

A identificação de ações de responsabilidade social de natureza estratégica ou responsiva pode ser observada nas empresas que compõem os setores de energia e cosméticos, com a predominância da estratégica em ambos. Esse resultado pôde ser obtido por meio da análise das informações divulgadas nas páginas web das organizações. Dentre as variáveis selecionadas para estudo, foram coletados dados que permitiram a comparação deles com o setor de atuação e o negócio principal da empresa.

Entende-se que o estudo contribui para uma melhor compreensão sobre a natureza da responsabilidade social nos setores de energia e 
cosméticos, ao descrever e analisar o caráter das ações desenvolvidas por duas empresas referência em sustentabilidade em seus respectivos setores. A discussão de cada um dos indicadores apresentados possibilita aos gestores que atuam nos setores estudados, e também aos que não atuam, uma visão clara da importância de uma gestão estratégica da RSE. Já que a maioria dos trabalhos publicados anteriormente possui como foco a descrição das ações de responsabilidade social de empresas modelo ou de um determinado setor, ou país. O presente estudo inova ao possibilitar uma reflexão sobre as características estratégicas ou responsivas das ações realizadas por organizações consideradas modelos em responsabilidade social.

No entanto, o trabalho possui limitações, pois os dados analisados são fornecidos pelas próprias organizações, o que impossibilita verificar a sua veracidade e a amplitude das reais ações adotadas por cada qual. A discussão desenvolvida remete à necessidade da realização de estudos que abordem a diferença entre responsabilidade social estratégica e responsiva, dado que é cada vez mais importante para as organizações adotarem a RSE.

\section{Referências}

BARROS, T.M.O. A divulgação de informação sobre responsabilidade social nas páginas web das empresas portuguesas: uma análise exploratória. 2008. 90 f. Dissertação (Mestrado em Contabilidade) - Faculdade de Economia, Universidade do Porto, Portugal, 2008. Disponível em:<http://repositorio-aberto.up.pt/bitstream/10216/7362/2/ Tese\%20de20Mestrado.pdf>. Acesso em: 02 mar. 2013.

CALIXTO, L. Responsabilidade Socioambiental: a divulgação de relatórios na América Latina. 2011. 316 f. Tese. (Doutorado em Administração de empresas) - Escola de Administração de Empresas de São Paulo, Fundação Getúlio Vargas, São Paulo, 2011. Disponível em:< http://bibliotecadigital.fgv.br/dspace/handle/10438/8190>. Acesso em: 01 mai. 2013. 
CARROLL, A.B. SHABANA, K.M. The business case for corporate social responsibility: a review of concepts, research and practice. International Journal of Management Reviews, Londres, v.12, n. 1, p. 85-104, jan, 2010.

CHEN, S. BOUVAIN, P. Is corporate responsibility converging? A comparison of corporate responsibility reporting in the USA, UK, Australia, and Germany. Journal of Business Ethics, Dordrecht ,v. 87, n. 1, p. 299-317, abr, 2009.

CERTO, S.C. PETER, J.C. Administração estratégica: planejamento e implementação de estratégias. 3 ed. São Paulo: Pearson Education do Brasil, 2010.

FARACHE, F. WANDERLEY, L.S.O. PERKS, K.J. SOUZA FILHO, J.M. Responsabilidade social das empresas na web: estratégias de divulgação adotadas pelas maiores empresas francesas no Brasil e na França. Gestão.org, Recife, v.5, n.3, p. 01-20, set/dez, 2007.

FEDATO, M.C.L. Responsabilidade social corporativa: benefício social ou vantagem competitiva? Um estudo das estratégias de atuação social empresarial e sua avaliação de resultados. 2005. 142 f. Dissertação (Mestrado em administração) - Departamento em Administração da Faculdade de Economia, Administração e Contabilidade, Universidade de São Paulo, São Paulo, 2005. Disponível em:< http://www.sel.eesc.sc.usp.br/informatica/graduacao/material/ etica/private/responsabilidade_social_corporativa_beneficio_social_ ou_vantagem_competitiva.pdf>. Acesso em: 07 mar. 2013.

FERRAZ, F.A.V.G.D.; RAFAEL, C.M.C.S. A comunicação online da Responsabilidade Social nas Empresas de Animação Turística em Portugal. In: CONFERÊNCIA INTERNACIONAL DE ANIMAÇÃO TURÍSTICA, 1, 2012, Peniche - Portugal. Anais... Peniche - Portugal: Escola Superior de Turismo e Tecnologia do Mar (ESTM), 2012. p.0120. Disponível em:<https://iconline.ipleiria.pt/bitstream/10400.8/683/1/ Paper\%20ESTM\%20A\%20Comunica\%C3\%A7\%C3\%A3o\% 20 
online $\% 20$ de $\% 20$ RSE $\% 20$ nas $\% 20$ EAT $\% 20$ em $\% 20$ Portugal.pdf $>$. Acesso em: 10 abr. 2013.

FRANÇA, A.S.T. FAVORETTO, J.R., BRAGA, S.S. Estratégias de responsabilidade social das empresas na internet: uma análise comparativa dos conteúdos dos websites corporativos no Brasil. Revista de Gestão Social e Ambiental. São Paulo, v.5, n.3, p. 150-167, set/ dez, 2011.

GODÓI-DE-SOUSA, E.; BUENO, J.M.; ALVES, M.B.F. A Evolução dos relatórios de sustentabilidade: uma avaliação em quatro empresas brasileiras do ramo de energia elétrica. Gestão Contemporânea, Porto Alegre, v.10, n.13, p.45-70, jan/jun , 2013. Disponível em:< http://seer4. fapa.com.br/index.php/arquivo/article/view/221/119>. Acesso em: 20 ago. 2013.

GONZAGA, A.M.; KIRSCHNER, A.M. Aspectos da geração de valor compartilhado através da Responsabilidade Socioambiental Empresarial Estratégica. In: CONGRESSO NACIONAL DE EXCELÊNCIA EM GESTÃO: ENERGIA. INOVAÇÃO, TECNOLOGIA E COMPLEXIDADE PARAA GESTÃO SUSTENTÁVEL, 6., 2010, Niterói( RJ). Anais... Niteroi ( RJ). 2010. p.1-17. Disponível em: <http://www.excelenciaemgestao. org/Portals/2/documents/cneg6/anais/T10_0261_1159.pdf>. Acesso em: 16 abr. 2013.

GUARNIER, P. Logística Reversa: em busca do equilíbrio econômico e ambiental. Recife: Clube de Autores, 2011p. 307.

KARKOTLI, G R.; FERREIRA, E; SOUZA, M. J. B. Responsabilidade social: uma estratégia empreendedora para a pequena empresa In: ENCONTRO DE ESTUDOS SOBRE EMPREENDEDORISMO E GESTÃO DE PEQUENAS EMPRESAS, 4., 2005, Curitiba. Anais... Curitiba, 2005, p. 885-895. Disponível em: <http://www.anegepe.org.br/ edicoesanteriores/curitiba/[75].pdf>. Acesso em: 06 mar. 2013.

KAUARK, F.S.; MANHÃES, F.C.; MEDEIROS, C.H. Metodologia da Pesquisa: um guia prático. Itabuna: Via Via Litterarum, 2010. Disponível 
em: <http://www.famescbji.edu.br/famescbji/biblioteca/livros_adm/ Livro\%20de\%20Metodologia\%20da\%20Pesquisa\%20-\%202010.pdf>. Acesso em: 05 jun. 2013.

LEE, M.P. A review of the theories of corporate social responsibility: its evolutionary path and the road ahead. International Journal of Management Reviews, Londres, v.10, n.1, p. 53-73, mar, 2008.

LORENZETTI, D. H.; CRUZ, R. M.; RICIOLI, S. Estratégia empresarial e sustentabilidade: um modelo integrador. Revista da Pós-graduação: Administração, Osasco, v. 2, n. 3, p. 33-57, jan/jun, 2008. Disponível em:< http://intranet.unifieo.br/legado/edifieo/index.php/posgraduacao/ article/view/218/291>. Acesso em: 07mar. 2013.

MARCONI, M.A.; LAKATOS, E.M. Metodologia científica. 5 ed. 2 reimp. São Paulo: Atlas, 2008.

MCWILLIAMS, A.; SIEGEL, D. WRIGHT, P. Corporate social responsibility: strategic implications. Journal of Management Studies, Durham, v. 43, n. 1, p. 1-18, jan, 2006.

MONTEIRO, B.F.B. Divulgação de Informação sobre Responsabilidade Social nas páginas web das empresas europeias do setor ferroviário: uma análise exploratória. 2010. 75 f. Dissertação (Mestrado em Gestão Comercial) - Faculdade de Economia, Universidade do Porto, Portugal, 2010. Disponível em: <http://repositorioaberto.up.pt/bitstream/10216/55117/2/Tese \%20 Mestrado\%20Gesto\%20Comercial2010Bruno\%20Monteiro080430017. pdf>. Acesso em: 01 mar. 2013.

MOURA-LEITE, R. C.; PADGETT, R. C. Historical background of corporate social responsibility. Social Responsibility Journal, Leicester, v. 7, n. 4, p. 528-539, 2011. Disponível em: <http://www.emeraldinsight.com/ doi/pdfplus/10.1108/1747111111117511>. Acesso em: 01 mar. 2013.

PEREIRA, J. L. et al. Estratégias e Práticas de Responsabilidade Social Corporativa: um estudo de Caso na Natura Cosméticos S/A. In: 
SEMINÁRIOS EM ADMINISTRAÇÃO, 12., 2009, São Paulo. Anais... São Paulo: FEA/USP, 2009. p. 1-16. Disponíveis em:< http://www. ead.fea.usp.br/semead/12semead/resultado/trabalhosPDF/880.pdf>. Acesso em: 14 maio. 2013.

PEREIRA, J.A.; SOUSA FILHO, J.M. Modelo de estratégia de Porter e Questões Sociais Empresariais: um ensaio teórico. In: ENCONTRO NACIONAL SOBRE GESTÃO EMPRESARIAL E MEIO AMBIENTE, 13., 2011, São Paulo. Anais... São Paulo:, 2011.p. 1-13. Disponível em: < http://www.engema.org.br/o-evento/organizacao/>. Acesso em: 15 mar. 2013.

PONTES, E.C.R. A Responsabilidade Social das Empresas e a Estratégia organizacional: análise de uma empresa na Amazônia. 2011. 111f. Dissertação (Mestrado em Administração) - Universidade da Amazônia, Belém, 2011. Disponível em: <http://www.unama.br/ novoportal/ensino/mestrado/programas/administracao/attachments/ article/110/Disserta \% C 3\% A 7\% C 3\% A3 o \% 20Elizabeth \% 20 Canguss\%C3\%BA\%20Reis\%20Pontes.pdf>. Acesso em: 04 mai. 2013.

PORTER, M.E.; KRAMER, M.R. Strategy \& Society: The link between Competitive Advantage and Corporate Social Responsibility, Harvard Business Review (HBR), Estados Unidos da América: Harvard Business Publishing. December, 2006. Disponível em: <https://hbr.org/2006/12/ strategy-and-society-the-link-between-competitive-advantage-andcorporate-social-responsibility>. Acesso em: 20 fev. 2013.

SANTIAGO, R.D. GOMES, E.R. Estratégias de responsabilidade socioambiental: análise comparativa dos conteúdos dos websites de entidades fechadas de previdência complementar. Revista Eletrônica Sistemas \& Gestão, Niterói, v. 4, n.1, p. 16-35, jan/abr, 2009.

SAUERBRONN, F.F.; FARIAA. A responsabilidade social é uma questão estratégica? Uma abordagem crítica. Revista de Administração Pública, Rio de Janeiro, v.42, n.1, p. 07-33, jan./fev. 2008. Disponível em: <http://www.scielo.br/pdf/rap/v42n1/a02v42n1.pdf>. Acesso em: 07 mar. 2013. 
SAVITZ, A.W.; WEBER K. A empresa sustentável: o verdadeiro sucesso é lucro com responsabilidade social e ambiental. Rio de Janeiro: Elsevier, 2007.

WANDERLEY, L.S.O. LUCIAN, R. FARACHE, F. SOUZA FILHO, J. M. CRS information disclosure on the web: a context-based approach analyzing the influence of country of origin and industry sector. Journal of Business Ethics, Dordrecht, v.82, n.2, p. 369-378, ago, 2008.

Artigo recebido em: 29/09/2013

Aprovado em: 16/06/2014 